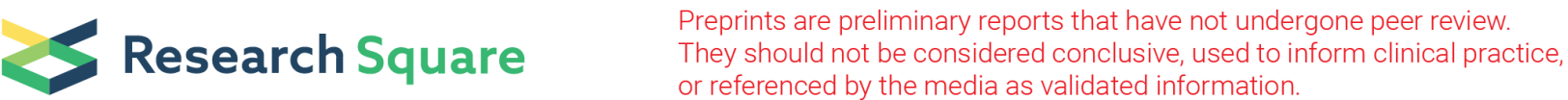

\section{The Effect of Simulated Seasonal Temperatures On Metarhizium Brunneum-Associated Mortality In Two Click Beetle Species, And A Degree-Day Infection Model}

\section{Todd Kabaluk ( $\sim$ Todd.Kabaluk@agr.gc.ca )}

Agriculture and Agri-Food Canada https://orcid.org/0000-0003-2895-8731

\section{Sophie Ruau}

Agriculture and Agri-Food Canada

Anita Poon

Agriculture and Agri-Food Canada

\section{Research Article}

Keywords: Entomopathogen, biocontrol, wireworm, integrated pest management, temperature profile, thermal gradient plate

Posted Date: November 12th, 2021

DOl: https://doi.org/10.21203/rs.3.rs-814733/v1

License: (c) (1) This work is licensed under a Creative Commons Attribution 4.0 International License.

Read Full License 


\section{Abstract}

Wireworms (Coleoptera: Elateridae), the larvae of adult click beetles are subterranean and generalist crop pests that can be difficult to target. Targeting adult beetles, however, may be an effective method to lower wireworm populations. Metarhizium brunneum (Petch) kills click beetles but the mortality rate was expected to vary according to temperature. Using a thermal gradient plate to simulate daily oscillating temperatures for April, May, and June, the effectiveness of M. brunneum strains LRC112 and F52 in causing mortality to Agriotes obscurus (L.) and A. lineatus (L.) beetles was studied. Mortality was fastest in beetles exposed to June temperatures and slowest in those exposed to April temperatures, with differences among beetle species $\times M$. brunneum strain combinations. Warmer temperatures resulted in more rapid mycelial outgrowth and conidiation in beetle cadavers, with only $A$. obscurus infected with $M$. brunneum LRC112 attaining near $100 \%$ conidiation. The number of degree days required to kill $50 \%$ of the beetles ( $\left.\mathrm{LDD}_{50}\right)$ was least for $A$. obscurus infected with M. brunneum LRC112 (176) followed by $A$. obscurus $x$ M. brunneum F52 (212), A. lineatus x M. brunneum LRC112 (215), and A. lineatus $\times M$. brunneum F52 (292). Hypothetical calculations showed that $M$. brunneum exposure earlier in the season resulted in a longer $L T_{50}$ but the earliest $L T_{50}$ calendar date. Later $M$. brunneum exposure dates resulted in lower $\mathrm{LT}_{50}$ 's, but later $\mathrm{LT}_{50}$ dates. This conceptual work demonstrates the importance of considering daily temperature oscillations, seasonality, and degree days in predicting the efficacy of entomopathogens to manage agricultural pests.

\section{Introduction}

Elaterid beetle larvae, or wireworms, are notorious pests that feed subterraneously on a large variety of agricultural crops. There are about 10,000 elaterid species occurring worldwide (Traugott et al. 2015). In the southern portion of Canada's east and west coasts, species in the genus Agriotes became the most important elaterid pests after they were introduced from Europe in the 19th century (Eidt 1953). They are now major pests whose larval stages can take from 3-5 years before pupation, during which they feed and cause crop loss. In the spring, wireworms attack the roots of vulnerable seedlings and can cause plant death; feeding activity later in the fall causes cosmetic damage to underground plant parts such as potato tubers (Parker and Howard 2002).

Since the middle of the $20^{\text {th }}$ century, the means to control wireworms have largely comprised chemical insecticides. Throughout that period, many have been deregistered in response to discovering negative human and environmental health effects, ensuing stricter regulatory policies. While previous chemistries have largely been persistent over several years, recent control products are not so residual, a quality that is alleged, in part, to be the reason for wireworms becoming more widespread, dense, and damaging (Vernon and van Herk 2013). Control products have always targeted elaterid larvae and it is only recently that attention has turned, experimentally, to targeting adults. In this shift, less traditional approaches have been tested e.g. mass beetle trapping and mating disruption using pheromones (Arakaki et al. 2008; 
Vernon et al. 2014; Leung et al. 2021), and biological control using entomopathogens (Kabaluk 2014; Kabaluk et al. 2015).

Biopesticides, with a market growth of about $17 \%$ per annum are increasingly being used as an alternative to, and compliment of chemical control products (Dunham Trimmer 2017). A variety of biocontrol methods to control wireworms such as natural predators, nematodes, bacteria, and fungi (Wraight et al. 2009; Kabaluk et al. 2013; la Forgia and Verheggen 2019). One of the most promising is the use of entomopathogenic fungi, which are currently used commercially in a variety of pest control systems e.g. for controlling of aphids, whiteflies, caterpillars, mites, and a variety of beetles (Faria and Wraight 2007; Kubicek and Druzhinina 2007).

Metarhizium brunneum (previously Metarhizium anisopliae var. anisopliae; Bischoff et al. 2009) is an entomopathogenic fungus that occurs naturally in soil worldwide and whose reproduction depends on killing and cycling through arthropod hosts. It has been well-studied as an insecticide targeting a variety of arthropod pests including the tick Rhipicephalus annulatus (Samish et al. 2014), Drosophila suzukii (Yousef et al. 2018), and wireworms (Rogge et al. 2017). M. brunneum has been shown to be virulent towards wireworms both in laboratory experiments (Ansari et al. 2009; Razinger et al. 2018) as well as in the field (Kabaluk et al. 2005; Kabaluk et al. 2007a; Brandl et al. 2017).

One of the major factors limiting the virulence of any biological control agent is temperature (Huffaker 2012; Lacey et al. 2015). M. brunneum has a limited effective temperature range that varies with strain (Ouedraogo et al. 1997). In culture, Metarhizium can grow between 5 and 40C, and the optimal temperatures are between 25 and 30C (Hallsworth and Magan 1999; Kabaluk et al. 2007b). The temperature conducive to Metarhizium infection of elm bark beetle (Scolytus scolytus) ranged from 10 to 20C, where temperatures below $10 \mathrm{C}$ did not result in infection, and those over 25 resulted in bacterial infection (Doberski 1981). In thrips (Megalurothrips sjostedti), pathogenic activity ranged from 2530C (Ekesi et al. 1999). In the vine weevil (Otiorhynchus sulcatus), both infection and mortality rates at different temperatures were strain dependent, but all showed a positive relationship with temperatures ranging from 10 to 25C (Moorhouse et al. 1994). Bugeme et al. (2009) examined the lethal times of Metarhizium infection for a range of insects using set temperatures. These studies suggest that application of entomopathogens for pest control outdoors would be most efficacious during the season(s) which temperatures are optimal for disease development. Set temperatures, however, are not representative, nor predictive of disease development in outdoor conditions where temperature changes by the hour. For example, how would a brief exposure to a temperature for optimal disease development be affected by a subsequent period of a suboptimal temperature? In making use of fluctuating temperatures, degree day models can predict both the phenological development of plants (Robinson 1971; Sharratt et al. 1989) and pest populations with relative accuracy (Pitcairn et al. 1992; Herms 2004). In studying the infection of locusts (Locusta migratoria) by M. anisopliae, Scanlan et al. (2001) found that simulated high day temperatures alternating with low simulated night temperatures resulted in locust mortality that was lower than if locusts were exposed to high temperatures alone. They therefore created 
an adjusted degree day model to predict mortality of locusts infected with $M$. anisopliae. There is little other research that considers cumulative heat in an insect infection model.

Our study aimed to demonstrate several points that are important when considering the use $M$. brunneum to target click beetles for wireworm control: i) that cooler early-seasonal applications take longer to kill beetles than warmer later-season applications; ii) that temperature-driven mortality can be translated into a predictive degree day model of infection; and iii) that different $M$. brunneum strain by beetle species combinations have different degree day requirements to produce an equal level of mortality. We believe that this information will help establish performance expectations when using $M$. brunneum as a biocontrol for click beetles. A secondary aim was to assess the performance characteristics our 'thermal gradient plate' - the apparatus used for simulating season temperatures.

\section{Materials And Methods}

\section{Simulation of seasonal temperatures}

A thermal gradient plate (TGP) (Mclaughlin et al. 1985; Ritchie et al. 2021; Stumborg et al. 2021) was used to simulate seasonal temperatures and contain experimental units (Petri plates containing beetles). The particular TGP TCMCl-176 model comprised $176-115 \mathrm{~mm}$ diameter $x$ 45mm deep cells, each of whose temperature can be controlled separately over a range from $-5 \mathrm{C}$ to $+40 \mathrm{C}$. For this experiment, 72 TGP cells were programmed to oscillate between simulated mean daily minimum and mean daily maximum air temperatures based on 30-year climate normals (1985-2015; weather.gc.ca) at Agassiz, British Columbia ( $\mathrm{N} 49.2400^{\circ}$, W $121.7567^{\circ}$ ) for 15-30 April ('April'), May, and June i.e. periods during spring and early summer when click beetles are active and vulnerable to surface-applied control efforts (Kabaluk 2016). The TGP was programmed so that the minimum temperature occurred at 4AM and the maximum temperature at 4PM. The temperature changed every $10 \mathrm{~min}$ as it oscillated in a sine wave pattern between these two set temperatures. Twenty-four cells were programmed for each of the three seasonal temperatures, with these 72 temperatures randomly assigned to the cells. Because there are no apparent physical gradients when using the TGP, the assignment of temperatures among the 72 cells was completely random. Thermocouples emanating from a Campbell Scientific $21 \mathrm{X}$ data logger (Edmonton, $A B$ ) logged the actual temperatures every $15 \mathrm{~min}$ inside the experimental units in two randomly selected TGP cells for each of the three seasonal temperatures, as temperatures were expected to deviate from set temperatures. The actual temperatures $(y)$ of daily maximum and minimum values were plotted against maximum and minimum set temperatures $(x)$ to validate the ability of the TGP to reproduce set temperatures in the experimental units. The mean logged temperatures $(y)$ were plotted against day $(x)$ and used in all analyses as they were temperatures to which the beetles were actually exposed.

Beetle collection and housing 
Male Agriotes obscurus and A. lineatus click beetles were collected during April and May 2015 from an experimental farm field located near Agassiz, BC using pitfall traps baited with pheromone bubble caps (Scotts Canada Ltd. Mississauga, ON). Beetles were retrieved daily from the traps and transferred to ventilated plexiglass boxes containing long grass leaves for cover, a wet paper towel for moisture, and apple pieces for food. The boxes were kept in a growth chamber at $8 \mathrm{C}$ (van Herk et al. 2008) until active beetles were selected for use in the experiments.

\section{Strain origins and culture}

Metarhizium brunneum LRC112 ('MbLRC112') originally isolated from an A. obscurus larval cadaver (Kabaluk et al., 2007) was mass produced on rice using a two stage fermentation process (Jackson and Jaronski 2012), yielding conidiated rice granules. M. brunneum F52 ('MbF52') is a widely recognized commercial biocontrol agent originating from a codling moth Cydia pomonella cadaver (European Food Safety Authority 2020). For the experiment, it was isolated from the granular product Met52 provided by Novozymes (Franklinton, NC, USA), and mass produced as for MbLRC112. Conidiated rice granules were dried to ca. $8 \% \mathrm{MC}$, vacuum packed in plastic bags and stored at ca. $8 \mathrm{C}$. Prior to use in the experiments, conidia viability was assessed by suspending conidiated granules in sterile water containing $0.01 \%$ Tween 20 to release and disperse conidia. A 100ul conidia suspension sample was spread on a Petri plate containing potato dextrose agar and incubated at $27 \mathrm{C}$ for $20 \mathrm{~h}$, after which the percent viability was determined.

\section{M. brunneum inoculation, apportionment of beetles, and dose assessment}

To inoculate beetles with $M$. brunneum, $5 \mathrm{~g}$ of conidiated rice granules were placed on filter paper contained in a $9 \mathrm{~cm}$ Petri plate. After the plate was shaken to release spores from the granules, the granules were removed, and eleven beetles were placed onto the filter paper. After the lid was placed to prevent escape, the beetles crawled on the paper for $3 \mathrm{~min}$ to acquire conidia. Ten of the inoculated beetles were then transferred to a clean modified Petri plate (see Experimental layout and unit apparatus, below) containing a cigarette filter moistened with distilled water and a $5 \mathrm{~mm} \times 10 \mathrm{~mm}$ cylinder of apple. The eleventh beetle was placed in a microcentrifuge tube containing $250 \mathrm{ul}$ of $0.05 \%$ Tween 20 water solution to assess conidia dose. This procedure was repeated 48 times - once for each $M$. brunneum strain (2) x click beetle species (2) x seasonal temperature (3) x Petri plate replicate (4) combination. The eight control groups were subjected to the same procedure, but without conidia. These comprised four groups of ten beetles for each click beetle species. Each Petri plate of 10 beetles constituted an experimental unit. In terms of timeline, day 0 was the day of conidia inoculation.

Ten of the 12 beetles representing each click beetle species $x M$. brunneum strain combination in the microcentifuge tubes were vortexed for 30 s to release conidia from their bodies, after which a suspension subsample was placed on a haemocytometer to assess the dose of conidia that each beetle acquired. The total conidia dose was adjusted to the viable conidia dose based on the percent germination determined for each $M$. brunneum strain. Data were log transformed and subjected to Shapiro-Wilk's test 
for normality and Levene's test for equal variances. The log transformed conidia dose data were subject to analysis of variance using R ver. 4.0.4 (R Core Team 2021) using the model:

$\log [$ conidia dose $($ conidia/beetle) $]=$ click beetle species $+M$. brunneum strain + Cbs $\times$ Mbs

Means of interaction terms were separated using Tukey's HSD test $(a=0.05)$.

\section{Experimental layout and unit apparatus}

Twenty-four experimental units (Petri plates), each comprising 10 beetles for each click beetle species (2) $x M$. brunneum strain (2; plus control $=3) \times$ replicate $(4)$ combination were individually and randomly assigned to TGP cells of a common seasonal temperature. With this assignment, and that of seasonal temperatures to TGP cells, the experiment was a completely random design. The Petri plates containing the beetles were modified by opening a $1 \mathrm{~cm}$ square ventilation hole covered in nylon mesh to permit air exchange. This was referred to as the 'lower plate'. An additional empty Petri plate was placed on top of the lower plate, referred to as the 'upper plate'. On the bottom of the upper plate three small rubber 'feet' (kitchen cupboard door bumper pads) elevated them from the top of the lower plate so that air could circulate through the ventilation hole in the lower plate. With the addition of moistened filter paper, the upper plate was used for incubating beetles found dead in the lower plate.

Mortality and disease development assessment and experiment maintenance

Beetles in the lower plate were scored as alive or dead when assessed every Monday, Wednesday, and Friday. Dead beetles were immediately placed in the upper Petri plate and scored as dead-asymptomatic, mycelial outgrowth, or sporulating during subsequent evaluations. On each evaluation day, the cigarette filter in the lower plate and filter paper in the upper plate were moistened as required, and apple replaced if it was moldy or deteriorating. On day 31, beetles maintained at April temperatures were removed and placed in a $25 \mathrm{C}$ incubator to verify the contribution of degree days to mortality and disease development. All beetles were assessed until day 35 . Mean beetle mortality outcomes $(y)$ with standard deviation were plotted against evaluation day $(x)$ for each seasonal temperature $\mathrm{x}$ beetle species $\times M$.

brunneum strain. Zero-intercept transition function (sigmoid) models were fit to the data using TableCurve 2D (Systat Software, San Jose, CA, USA). The percent of subdivided dead categories were plotted against evaluation day.

Degree day calculations and model plotting

Cumulative degree days for each seasonal temperature were calculated over the duration of the experiment using the mean logged temperature from each pair of randomly selected TGP cells. The base temperature $\left(\mathrm{T}_{0}\right)$ of $5 \mathrm{C}$ was previously derived from i) thermal profiles of $M b L \mathrm{LC} 112$ and $M b F 52$ colony growth (Kabaluk et al. 2007b); and ii) empirical data assessing the mortality of $A$. obscurus and $A$. lineatus caused by MbLRC112 and MbF52 over a range of low temperatures (T. Kabaluk, unpublished). The cumulative degree day calculation was: 
$\sum\left[(\right.$ recorded time point temperature -5$\left.) / 96^{\star}\right]$

*temperatures were logged every $15 \mathrm{~min}$, or $1 / 96$ of a $24 \mathrm{~h}$ day

To plot the data, cumulative degree days was used as the $x$ coordinate, and the associated mean beetle mortality from four replicate Petri plates for each M. brunneum strain $\mathrm{x}$ beetle species as the $y$ coordinate. In doing so, data from the three seasonal temperature treatments were pooled. Zero-intercept transition function (sigmoid) models were fit to the data using TableCurve 2D. The 95\% confidence interval shading was generated in $\mathrm{R}$ using the TableCurve 2D model fit results. Degree-day regressions were analyzed with a generalized linear model followed by pairwise comparisons using the package emmeans in $\mathrm{R}$ with a Tukey's adjustment.

\section{Hypothetical field application of M. brunneum}

The number of degree days to kill $50 \%$ of the beetle population $\left(\operatorname{LDD}_{50}\right)$ were interpolated from data predicted by transition function models of the beetle mortality vs. degree days plots. Three hypothetical, but realistic $M$. brunneum field application dates were then chosen and the number of accumulated degree days (using actual outdoor temperatures in Agassiz, BC in 2019) from each application date plotted (the degree days for the start of each application date was set to zero). $\operatorname{LDD}_{50}$ for each species*strain combination were used to interpolate the time (days) to kill $50 \%$ of the beetle population $\left(\mathrm{LT}_{50}\right)$, and matched to an associated date.

Figures were created using Microsoft Powerpoint and R.

\section{Results}

Simulated seasonal temperatures and performance characteristics of thermal gradient plate

Actual seasonal maximum and minimum temperatures varied from set temperatures - to a lesser degree in the lower Petri plate that directly contacted the base of the TGP cell (Fig. 1). The high coefficient of determination of the linear regressions suggested good precision in predicting the variation that can be expected over the range of temperatures tested. Actual diurnal temperature fluctuations of each of the three seasonal temperatures are shown in Fig. 2. This pattern held throughout the experiment with the difference among temperatures across equal time points ranging from $0.02 \mathrm{C}-0.63 \mathrm{C}$.

Conidia viability and dose

The mean number of total conidia with which beetles were inoculated was not different between beetles species $(F=0.8536, d f=1, p=0.8536)$, but significantly different between strains $(F=4.895, d f=1, p=$ 0.03356), with $M b L R C 112$ contributing 40,813 conidia/beetle and MbF52 29,500/beetle. A Tukey's HSD test showed no significant differences among species*strain combinations (Table 1 ). 
MbLRC112 conidia were determined to be $45 \%$ viable, and MbF52 $80 \%$ viable. The mean number of viable conidia with which beetles were inoculated was not different between species $(F=0.586, d f=1$, $p=0.449)$, but significantly different between strains ( $F=8.385, d f=1, p=0.00639)$. A Tukey's HSD test showed a single significant difference between AO-MbF52 and AO-MbLRC112 ( $p=0.03255)$.

\section{Beetle mortality as a function of time}

In all species*strain combinations, the rate of beetle mortality was greatest under a June temperature profile, followed by May, then April (Fig. 3). After 35 days, mortality of the control beetles was $20 \%$ or lower. Comparing species, $A$. obscurus beetles died at a greater rate than $A$. lineatus from both $M b F 52$ and $M b L R C 112$ strains. There was a larger difference in mortality rates between the two species when treated with $M b F 52$ than with $M b L R C 112$. Comparing strains, the rate of mortality of beetles treated with $M b L R C 112$ was greater than those treated with $M b F 52$ in A. lineatus, but only moderately greater in $A$. obscurus.

\section{Disease development}

The disease progression in all species*strain combinations was similar in that once the beetles died, they were asymptomatic for 3-10 days, followed by the presence of mycelial outgrowth for 2-10 days before fungal sporulation (Fig 4). The speed of disease progression depended mainly on the seasonal temperature, with much slower progression in the cooler April profile compared to the warmer May and June profiles. The speed of disease progression varied slightly between beetle species and fungal strain and appeared to vary more between species than strain. A. lineatus exposed to MbF52 showed the slowest disease progression of all species*strain combinations. A. obscurus exposed to MbF52 showed a moderate speed of disease progression which appeared similar to that of $A$. lineatus exposed to MbLRC112. A. obscurus exposed to MbLRC112 showed the fastest disease progression and highest percent of sporulating beetles.

Beetle mortality as a function of degree days

Each species*strain combination showed a distinct relationship between degree days and percent mortality of beetles (Fig. 5). In both species, the rate of mortality in beetles exposed to MbLRC112 was greater compared to $M b F 52$, with a larger difference in $A$. lineatus. A. obscurus appeared to succumb to both strains at a faster rate compared to $A$. lineatus. A generalized linear model followed by pairwise comparisons of percent mortality using a Tukey's adjustment showed significant differences in all species*strain combinations ( $p<0.0001)$ except for AL MbLRC112 and AO MbF52 ( $z=0.891, p=0.8096)$.

Hypothetical field application of M. brunneum

$\mathrm{LDD}_{50}$ values for each species*strain combination are shown in Fig. 6. The lowest $\operatorname{LDD}_{50}$ (176) was for $A$. obscurus exposed to MbLRC112, followed by A. obscurus x MbF52 (212), A. lineatus x MbLRC112 (215), and $A$. lineatus $\times$ MbF52 (292). Beetles that would be exposed to $M$. brunneum on the latest date had the 
lowest $\mathrm{LT}_{50}$, with the minimum of 12 days for $A$. obscurus exposed to MbLRC112 on April 29 in our hypothetical example. In general, the later beetles are exposed to M. brunneum, the shorter was the $\mathrm{LT}_{50}$ because of the more rapid accumulation of heat units later in the season. Despite taking longer to kill beetles, earlier application dates still resulted in an earlier calendar date when $\mathrm{LT}_{50}$ was attained.

\section{Discussion}

Given the differences in $\mathrm{LDD}_{50}$ values among click beetle $\mathrm{x}$ M. brunneum strain combinations, we believe unique $L D_{50}$ values can also be used as a quality for strain selection as there were clear differences in both $M$. brunneum virulence (by virtue of a greater rate of beetle mortality caused by MbLRC112 compared to MbF52) and beetle susceptibility (by virtue of a greater rate of mortality of $A$. obscurus compared to $A$. lineatus). We are aware that the derived $\mathrm{LDD}_{50}$ and $\mathrm{LT}_{50}$ values are not definitive and need further refinement and validation - both under laboratory and field conditions. However, we believe this study elucidates a sound concept alerting other researchers to consider $\operatorname{LDD}_{50}$ so that entomopathogens might serve the pest control purpose for which they are intended - particularly since there is little to no reports of degree day infection models.

Our models provided a reasonable fit to data derived from all seasonal temperatures and associated beetle mortality (Fig. 5). Degree days and associated mortality of beetles exposed to April temperatures and placed in the 27C incubator on Day 31 were closely associated with the fitted models for three of the beetle species $\mathrm{x} M b$ strain combinations, supporting degree days as a variable driving beetle mortality. The exception was for $A$. obscurus $\times$ MbF52, where the $x, y$ coordinates for the April-incubator treatment deviated noticeably from the model. While reasons for the deviation is not clear, it is possible that a degree day $\mathrm{x}$ beetle $\mathrm{x}$ species $\mathrm{x} M$. brunneum strain interaction occurred. A closer fit of these points to the model would have been achieved with a slightly greater mortality of $A$. lineatus exposed to MbF52.

The application of our work is intended to be aimed at female beetles. Their M. brunneum induced mortality would result in reduced input of new larvae into the soil thereby lowering wireworm soil populations over years. We used male beetles in our experiment because they were easy to amass in pitfall traps using pheromones, while it is exceedingly difficult to acquire an equal number of female beetles that can only be trapped passively as attractants are unavailable. We consider that in using males, our intended application was served since the mortality rate of females is the same for males (Janmaat et al. 2021 under review). Zurowski et al. (2020) found that female A. obscurus whose life span was shortened by M. brunneum exposure maintained fecundity levels by a shortening of the preoviposition period. While this seemingly negates using entomopathogens for lowering larval populations, exposure of beetles to increased temperature i.e. application latter in the season, might offset maintained fecundity by accelerating $L D D_{50}$ and $L T_{50}$. Research is needed to determine if this would be the case.

While we advocate for the importance of the degree days in predicting M. brunneum - associated mortality of pestilent species of adult elaterids (and other entomopathogen-pest combinations), there are 
further considerations to accompany our models: i) Fig. 6 assumes $L T_{50}$ values based on air temperature, but the spatial occurrence of beetles would be in thatch, under the plant canopy, and on/in soil - each with variable temporal occurrence. Spatial and temporal temperature variations would result in $\mathrm{LT}_{50}$ values different from the air temperature-derived values that we report; ii) beetles used in our experiment were exposed to a fixed dose of M. brunneum conidia. Insect mortality in general (Arthurs and Thomas 2001; Ekesi et al. 2002; Behle and Goett 2016), and wireworms in particular (Kabaluk, unpublished), is well known to increase with inoculum dose and dose changes would result in mortality rates different than what we have presented. It would be expected that the dose of conidia received by beetles during an in situ agronomic application, particularly a spray application of a conidia suspension, would be significantly lower than those used in our experiment, and therefore a slower rate of beetle mortality; iii) the $L T_{50}$ values apply to the beetles receiving inoculum. Since beetle emergence is sequential in situ (Brian 1947), only a portion of the population would be targeted during an agronomic application of inoculum, particularly during early applications when a large proportion of the beetle population is yet to emerge and be vulnerable to receiving/acquiring inoculum. In the absence of rapid and durable horizontal transmission (Leung et al. 2021), multiple applications of inoculum would be necessary.

Disease progression (mycelial outgrowth, sporulation from beetle cadavers; Fig. 4) increased as seasonal temperatures increased from April to June. Sporulation of cadavers might be important in reducing the population density of click beetles as Leung et al. (2021) found that M. brunneum disease can spread among $A$. obscurus via environmental contamination i.e. shedding of conidia from cadavers to the surrounding environment. Give their finding, it is important to note that almost no sporulation occurred at April temperatures so the opportunity for environment transmission is only possible later in the season. Furthermore, beetle cadavers were incubated in the upper plate of each TGP cell, where temperatures were warmer than the lower plate (Fig. 1). In fact, the actual minimum and maximum temperatures of the upper plate for April were $11.7 \mathrm{C}$ and $19.8 \mathrm{C}$ - only slightly cooler than the actual minimum and maximum temperatures of the lower plate for June (12.4C and 20.9C), the latter of which were more representative of the long-term average of June temperatures. This suggests that the sporulation of cadavers would likely not occur in beetles exposed to actual June temperatures in the field. It also reveals the caution required when using the TGP model TCMCl-176 to assign temperature profiles when using an experimental configuration such as ours i.e. with an upper Petri plate: the actual temperature will deviate significantly upward from the set temperature. The deviation can be expected to be less pronounced in the lower plate since it is in direct contact with the TGP cell. The magnitude of such deviation is evident in the regression parameters shown in Figure 1. A perfectly performing system would have a slope of 1 and a $y$-intercept of zero i.e. the set temperature would perfectly match the actual temperature. The Fig. 1 equations provide insight into how to achieve desired actual temperatures, $y$, by choosing an appropriate set temperature, $x$. The set temperature vs. actual temperature disparity can be expected to be different according to the experimental apparatus used. In our case, the objective would have been better served by assigning the upper plates to their own cells where their temperature profiles would have matched seasonal set temperatures in the same way as for the lower plate. 
Our work demonstrates the importance of considering seasonal temperature in advance of using fungal entomopathogens to target insect pests for crop protection. Temperature normals can be used to predict entomopathogen efficacy in a given season or climatic zone. Degree days can used for a similar purpose, but can also characterize entomopathen $x$ pest species combinatidons so that the entomopathogen strain used is appropriate to the pest in a particular season or climate. Degree days can be used to predict $L T_{50}$ which can then be related to the duration of the preoviposition period to determine if an entomopathogen will serve its intended purpose of reducing the input of new larvae. The thermal gradient plate was a useful tool for simulating seasonal temperatures, however the set temperature vs. actual temperature relationship should be determined in advance of conducting an experiment so that the desired target temperature is achieved in the experimental unit.

\section{Declarations}

\section{Funding}

This research was funded by the Agriculture and Agri-Food Canada's Agri-Innovation Program, with additional contributions from Canadian food producers and agri-food businesses.

\section{Conflicts of interest/Competing interests}

The authors see no conflict of interest in conducting and reporting the work.

\section{Availability of data and material}

Original data from which the reported information was derived can be made available if requested from the contact author.

\section{Code availability}

Not applicable

\section{Ethics approval}

This research conforms to Agriculture and Agri-Food Canada's ethics policies for research and publication

\section{Consent to participate}

The beetles did not consent to participate in the experiment. On the contrary, they were betrayed by the lure of the synthetic pheromone.

\section{Consent for publication}

All authors consent to the publication of the material presented

\section{Authors' Contributions}

TK conceived, designed, and coordinated the experiments and acquired funding. SR carried out the experiments and wrote an initial report from which this paper was elaborated. AP analyzed data and created graphs. AP and TK wrote, prepared, and submitted the final manuscript. 


\section{Acknowledgements}

We recognize the contributions of Beth McCannel and Joanna Wong for their assistance in the preparation of materials involved in the experiment and evaluation of beetles. We also thank Gosia Zdanowicz for programming, maintenance, scheduling of the thermal gradient plate.

\section{References}

1. Ansari MA, Evans M, Butt TM (2009) Identification of pathogenic strains of entomopathogenic nematodes and fungi for wireworm control. Crop Prot 28(3):269-272. https://doi.org/10.1016/j.cropro.2008.11.003

2. Arakaki N, Nagayama A, Kobayashi A, Kishita M, Sadoyama Y, Mougi N, Kawamura F, Wakamura S, Yamamura K (2008) Control of the sugarcane click beetle Melanotus okinawensis Ohira (Coleoptera: Elateridae) by mass trapping using synthetic sex pheromone on Ikei Island, Okinawa, Japan. Appl Entomol Zool 43(1):37-47. https://doi.org/10.1303/aez.2008.37

3. Arthurs S, Thomas MB (2001) Effect of Dose, Pre-mortem host incubation temperature and thermal behaviour on host mortality, mycosis and sporulation of Metarhizium anisopliae var. acridum in Schistocerca gregaria. Biocontrol Sci Technol 11(3):411-420.

https://doi.org/10.1080/09583150120055826

4. Behle RW, Goett EJ (2016) Dosage response mortality of Japanese beetle, masked chafer, and June beetle (Coleoptera: Scarabaeidae) adults when exposed to experimental and commercially available granules containing Metarhizium brunneum. J Econ Entomol 109(3):1109-1115. https://doi.org/10.1093/jee/tow080

5. Brandl MA, Schumann M, Przyklenk M, Patel A, Vidal S (2017) Wireworm damage reduction in potatoes with an attract-and-kill strategy using Metarhizium brunneum. J Pest Sci 90(2):479-493. https://doi.org/10.1007/s10340-016-0824-x

6. Brian MV (1947) On the ecology of beetles of the genus Agriotes with special reference to $A$. obscurus. J Anim Ecol 16(2):210-224. https://doi.org/10.2307/1496

7. Bugeme DM, Knapp M, Boga HI, Wanjoya AK, Maniania NK (2009) Influence of temperature on virulence of fungal isolates of Metarhizium anisopliae and Beauveria bassiana to the two-spotted spider mite Tetranychus urticae. Mycopathologia 167(4):221-227. https://doi.org/10.1007/s11046008-9164-6

8. Doberski JW (1981) Comparative laboratory studies on three fungal pathogens of the elm bark beetle Scolytus scolytus: Effect of temperature and humidity on infection by Beauveria bassiana, Metarhizium anisopliae, and Paecilomyces farinosus. J Invertebr Pathol 37(2):195-200. https://doi.org/10.1016/0022-2011(81)90075-6

9. Dunham Trimmer. 2017. Biological control global market overview. Dunham Trimmer LLC. DunhamTrimmer.com 
10. Eidt DC (1953) European Wireworms in Canada with particular reference to Nova Scotian Infestations. Can Entomol 85(11):408-414. https://doi.org/10.4039/Ent85408-11

11. Ekesi S, Maniania NK, Ampong-Nykaro K (1999) Effect of temperature on germination, radial growth and virulence of Metarhizium anisopliae and Beauveria bassiana on Megalurothrips sjostedti. Biocontrol Sci Technol 9(2):177-185. https://doi.org/10.1080/09583159929767

12. Ekesi S, Maniania NK, Lux SA (2002) Mortality in three African tephritid fruit fly puparia and adults caused by the entomopathogenic fungi, Metarhizium anisopliae and Beauveria bassiana. Biocontrol Sci Technol 12(1):7-17. https://doi.org/10.1080/09583150120093077

13. European Food Safety Authority et al (2020) Peer review of the pesticide risk assessment of the active substance Metarhizium brunneum BIPESCO 5 / F52. EFSA Journal 18:6274-6298.

14. Faria MR de, Wraight SP (2007) Mycoinsecticides and Mycoacaricides: A comprehensive list with worldwide coverage and international classification of formulation types. Biol Control 43(3):237256. https://doi.org/10.1016/j.biocontrol.2007.08.001

15. Hallsworth JE, Magan N (1999) Water and temperature relations of growth of the entomogenous fungi Beauveria bassiana, Metarhizium anisopliae, and Paecilomyces farinosus. J Invertebr Pathol 74(3):261-266. https://doi.org/10.1006/jipa.1999.4883

16. Herms DA (2004) Using degree-days and plant phenology to predict pest activity. Minn Agric Exp Stn Publ :49-59

17. Huffaker CB (2012) Theory and Practice of Biological Control. Elsevier. https://doi.org/10.1016/B978-0-12-360350-0.X5001-6

18. Jackson MA, Jaronski ST (2012) Development of pilot-scale fermentation and stabilisation processes for the production of microsclerotia of the entomopathogenic fungus Metarhizium brunneum strain F52. Biocontrol Sci and Technol 22:915-930.

https://doi.org/10.1080/09583157.2012.696578

19. Kabaluk T (2014) Targeting the click beetle Agriotes obscurus with entomopathogens as a concept for wireworm biocontrol. BioControl 59(5):607-616. https://doi.org/10.1007/s10526-014-9603-x

20. Kabaluk T (2016) Autumn activity of adult Agriotes lineatus (Linnaeus) (Coleoptera: Elateridae) in Southwestern British Columbia. Coleopt Bull 70(3):634-637. https://doi.org/10.1649/0010-065X70.3.634

21. Kabaluk T, Ericsson, JD (2007) Environmental and behavioral constraints on the infection of wireworms by Metarhizium anisopliae. Environ Entomol 36:1415-1420. https://doi.org/10.1603/0046-225x(2007)36[1415:eabcot]2.0.co;2

22. Kabaluk T, Goettel M, Erlandson M, Ericsson J, Duke GM, Vernon RS (2005) Metarhizium anisopliae as a biological control for wireworms and a report of some other naturally-occurring parasites. IOBCwprs Bull 28:109-115

23. Kabaluk T, Vernon R, Goettel M (2007a) Mortality and infection of wireworm, Agriotes obscurus [Coleoptera: Elateridae], with inundative field applications of Metarhizium anisopliae. Phytoprotection 88(2):51-56. https://doi.org/10.7202/018055ar 
24. Kabaluk T, Goettel M, Ericsson JD, Erlandson M, Cassidy F, Vernon B, Jaronski S, MacKenzie K (2007b) Promise versus performance: working toward the use of Metarhizium anisopliae as a biological control for wireworms. Integr Control Soil Insect Pests IOBCwprs Bull 30(7):69-77

25. Kabaluk T, Janmaat A, Sheedy S, Goettel M, Noronha C (2013) Agriotes spp. L., Wireworms and click beetles (Coleoptera: Elateridae) in P.G. Mason and D.R. Gillespie (eds.) Biological Control Programmes in Canada 2001 - 2012. CABI Publishing.

26. Kabaluk T, Lafontaine JP, Borden JH (2015) An attract and kill tactic for click beetles based on Metarhizium brunneum and a new formulation of sex pheromone. J Pest Sci 88(4):707-716. https://doi.org/10.1007/s10340-015-0661-3

27. Kubicek CP, Druzhinina IS (eds) (2007) Entomopathogenic fungi and their role in pest control. In: Environmental and Microbial Relationships. Springer, Berlin, Heidelberg, pp 159-187

28. Lacey LA, Grzywacz D, Shapiro-llan DI, Frutos R, Brownbridge M, Goettel MS (2015) Insect pathogens as biological control agents: Back to the future. J Invertebr Pathol 132:1-41. https://doi.org/10.1016/j.jip.2015.07.009

29. Leung JPS, Janmaat AF, Kabaluk JT, Cory JS (2021) The effect of synthetic female sex pheromone on the transmission of the fungus Metarhizium brunneum by male Agriotes obscurus click beetles. $J$ Invertebr Pathol 179:107534. https://doi.org/10.1016/j.jip.2021.107534

30. Mclaughlin NB, Bowes GR, Thomas AG, Dyck FB, Lindsay TM, Wise RF (1985) A new design for a seed germinator with 100 independently temperature controlled cells. Weed Res 25(3):161-173. https://doi.org/10.1111/j.1365-3180.1985.tb00632.x

31. Moorhouse ER, Gillespie AT, Charnley AK (1994) The influence of temperature on the susceptibility of vine weevil, Otiorhynchus sulcatus (Fabricius) (Coleoptera: Curculionidae), larvae to Metarhizium anisopliae (Deuteromycotina: Hyphomycetes). Ann Appl Biol 124(2):185-193. https://doi.org/10.1111/j.1744-7348.1994.tb04127.x

32. Ouedraogo A, Fargues J, Goettel MS, Lomer CJ (1997) Effect of temperature on vegetative growth among isolates of Metarhizium anisopliae and M. flavoviride. Mycopathologia 137:37-43

33. Parker WE, Howard JJ (2002) The biology and management of wireworms (Agriotes spp.) on potato with particular reference to the U.K. Agric For Entomol 3(2):85-98. https://doi.org/10.1046/j.14619563.2001.00094.x

34. Pitcairn MJ, Zalom FG, Rice RE (1992) Degree-day forecasting of generation time of Cydia pomonella (Lepidoptera: Tortricidae) populations in California. Environ Entomol 21(3):441-446. https://doi.org/10.1093/ee/21.3.441

35. R Core Team (2021) R: A language and environment for statistical computing. R Foundation for Statistical Computing. Vienna, Austria. www.R-project.org.

36. Razinger J, Schroers HJ, Urek G (2018) Virulence of Metarhizium brunneum to field collected Agriotes spp. Wireworms. Journal of Agricultural Science and Technology 20(2):309-320

37. Ritchie MW, Dawson JW, MacMillan HA (2021) A simple and dynamic thermal gradient device for measuring thermal performance in small ectotherms. Curr Res Insect Sci 1:100005. 
https://doi.org/10.1016/j.cris.2020.100005

38. Robinson RG (1971) Sunflower Phenology-Year, vvariety, and date of planting effects on day and growing degree-day summations. Crop Sci 11(5):635-638.

https://doi.org/10.2135/cropsci1971.0011183X001100050009x

39. Rogge SA, Mayerhofer J, Enkerli J, Bacher S, Grabenweger G (2017) Preventive application of an entomopathogenic fungus in cover crops for wireworm control. BioControl 62(5):613-623. https://doi.org/10.1007/s10526-017-9816-x

40. Samish M, Rot A, Ment D, Barel S, Glazer I, Gindin G (2014) Efficacy of the entomopathogenic fungus Metarhizium brunneum in controlling the tick Rhipicephalus annulatus underfield conditions. Vet Parasitol 206:258-266. https://doi.org/10.1016/j.vetpar.2014.10.019

41. Scanlan JC, Grant WE, Hunter DM, Milner RJ (2001) Habitat and environmental factors influencing the control of migratory locusts (Locusta migratoria) with an entomopathogenic fungus (Metarhizium anisopliae). Ecol Model 136(2):223-236. https://doi.org/10.1016/S03043800(00)00424-5

42. Sharratt BS, Sheaffer CC, Baker DG (1989) Base temperature for the application of the growingdegree-day model to field-grown alfalfa. Field Crops Res 21(2):95-102. https://doi.org/10.1016/0378-4290(89)90045-2

43. Stumborg MA, Vankosky MA, Jones A, Olfert O, Thomas AG (2021) Design and performance of a 96 cell thermally controlled multi-cell instrument. Canadian Biosystems Engineering. In press.

44. Traugott M, Benefer CM, Blackshaw RP, van Herk WG, Vernon RS (2015) Biology, ecology, and control of elaterid beetles in agricultural land. Annu Rev Entomol 60:313-334

45. van Herk WG, Kabaluk JT, Lam VWM, Vernon RS (2008) Survival of male click beetles, Agriotes obscurus L. (Coleoptera: Elateridae) during and after storage at different temperatures. Journal of the Entomological Society of British Columbia 105:113-114

46. Vernon RS, Blackshaw RP, Herk WG van, Clodius M (2014) Mass trapping wild Agriotes obscurus and Agriotes lineatus males with pheromone traps in a permanent grassland population reservoir. Agric For Entomol 16(3):227-239. https://doi.org/10.1111/afe.12058

47. Vernon RS, van Herk WG (2013) Wireworms as pests of potato. In: Alyokhin A, Vincent C, Giordanengo P (eds) Insect Pests of Potato. Academic Press, San Diego, pp 103-164

48. Wraight SP, Lacey L.A., Kabaluk JT, Goettel MS (2009) Potential for microbial biological control of coleopteran and hemipteran pests of potato. Fruit, Veg and Cereal Sci and Biotechnol 3 (Special Issue 1):25-38.

49. Yousef M, Aranda-Valera E, Quesada-Moraga E (2018) Lure-and-infect and lure-and-kill devices based on Metarhizium brunneum for spotted wing Drosophila control. J Pest Sci 91(1):227-235. https://doi.org/10.1007/s10340-017-0874-8

50. Zurowski K, Janmaat AF, Kabaluk T, Cory JS (2020) Modification of reproductive schedule in response to pathogen exposure in a wild insect: Support for the terminal investment hypothesis. $J$ Evol Biol 33(11):1558-1566 


\section{Table}

Table 1. Metarhizium brunneum conidia dose (number of conidia per beetle and viable conidia) per Agriotes spp. beetle for each beetle species x M. brunneum strain (LRC112 and F52) combination. Means followed by the same letter are not significantly different.

\begin{tabular}{lll} 
Species x strain & Mean \pm s.d. total conidia/beetle & Mean \pm s.d. viable conidia/beetle \\
\hline A. obscurus x LRC112 & $35,750 \mathrm{a} \pm 13,594$ & $16,088 \mathrm{a} \pm 6,117$ \\
\hline A. obscurus x F52 & $29,625 \mathrm{a} \pm 46,417$ & $23,700 \mathrm{~b} \pm 3,713$ \\
\hline A. lineatus x LRC112 & $45,875 \mathrm{a} \pm 27,664$ & $20,644 \mathrm{ab} \pm 12,449$ \\
\hline A. lineatus x F52 & $29,375 \mathrm{a} \pm 10,193$ & $23,500 \mathrm{ab} \pm 8,155$
\end{tabular}

Figures 


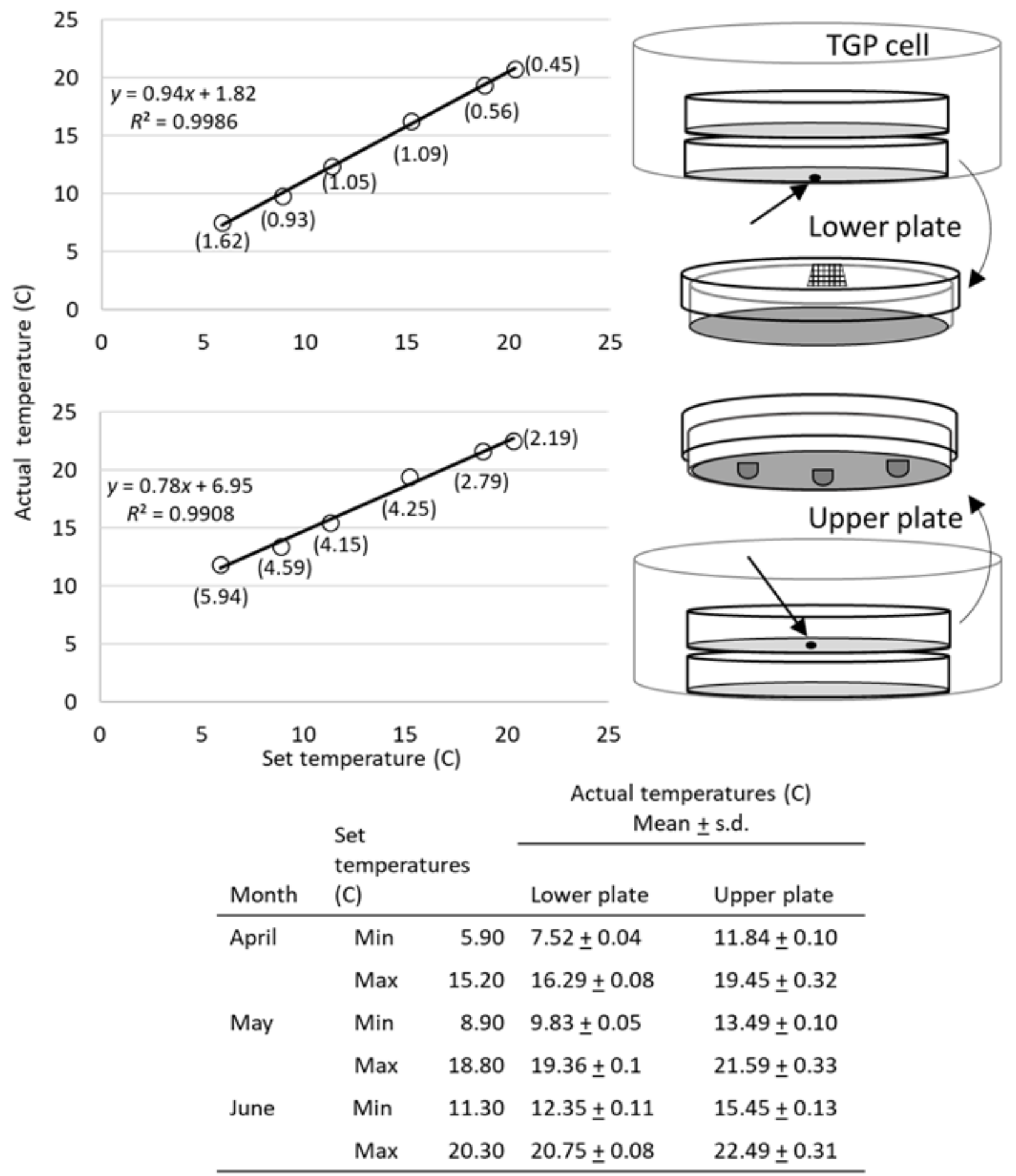

\section{Figure 1}

Thermal gradient plate set temperatures and responding actual temperatures inside experimental units (Petri plates), and experimental unit configuration. Numbers in brackets indicate deviation from set temperatures. Straight arrows indicate position of thermocouple used to measure actual temperature. Curved arrows indicate modifications of experimental units; mesh for ventilation in the lid of lower plate; rubber feet on the bottom of upper plate 


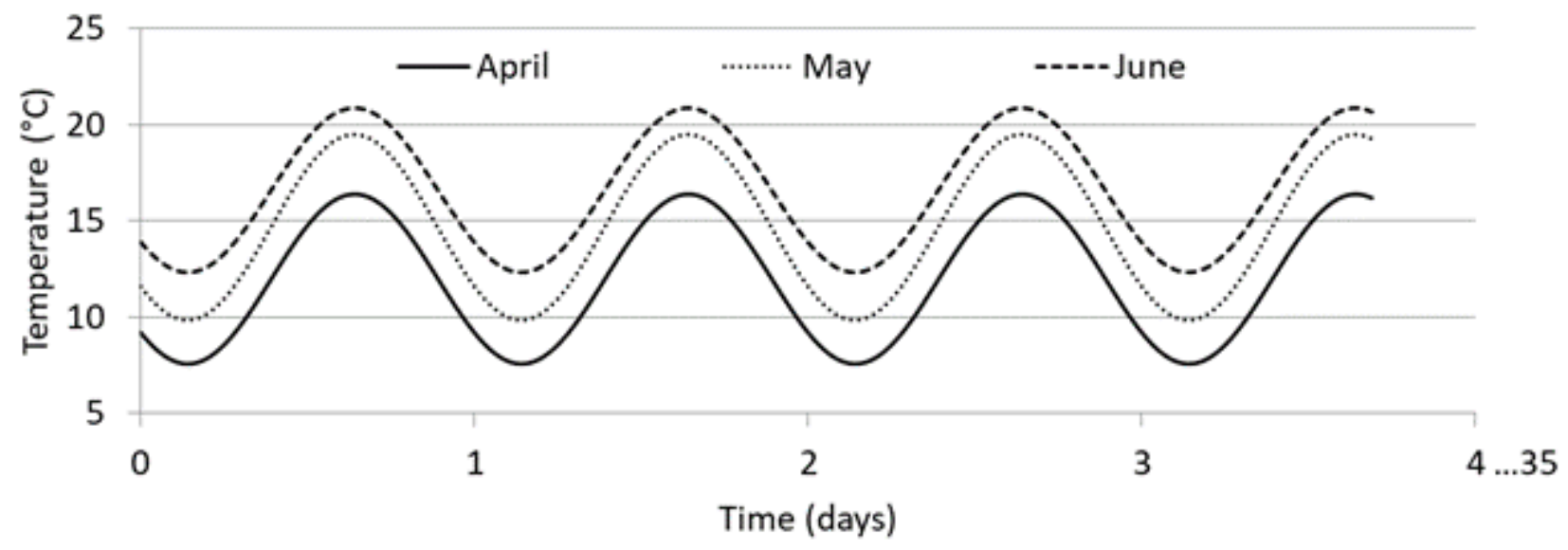

Figure 2

Temperatures to which Agriotes spp. beetles were exposed inside the lower Petri plate during the experiment 

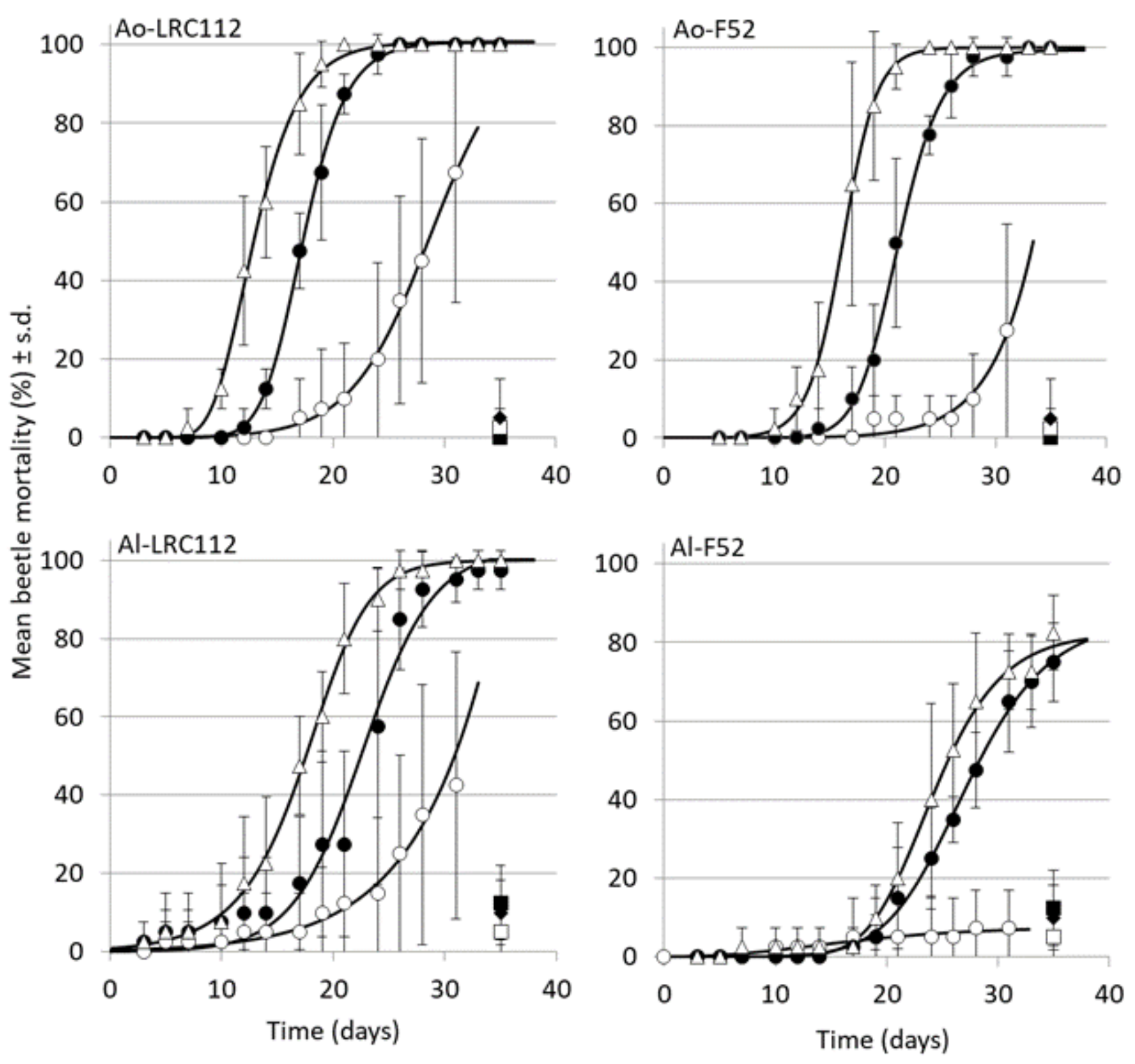

Figure 3

Mean percent mortality of Agriotes obscurus (Ao) and A. lineatus (Al) exposed to Metarhizium brunneum (strains LRC112 and F52) and different seasonal temperatures as a function of time: April (๑), May (๑), and June $(\triangle)$. Non-dosed beetles for April $(\square)$, May $(\square)$, and June $(\mathbb{\nabla})$ at the end of the experiment, day 35. The results of the April plates are not shown after day 31 because they were moved to a $25 \mathrm{C}$ incubator 


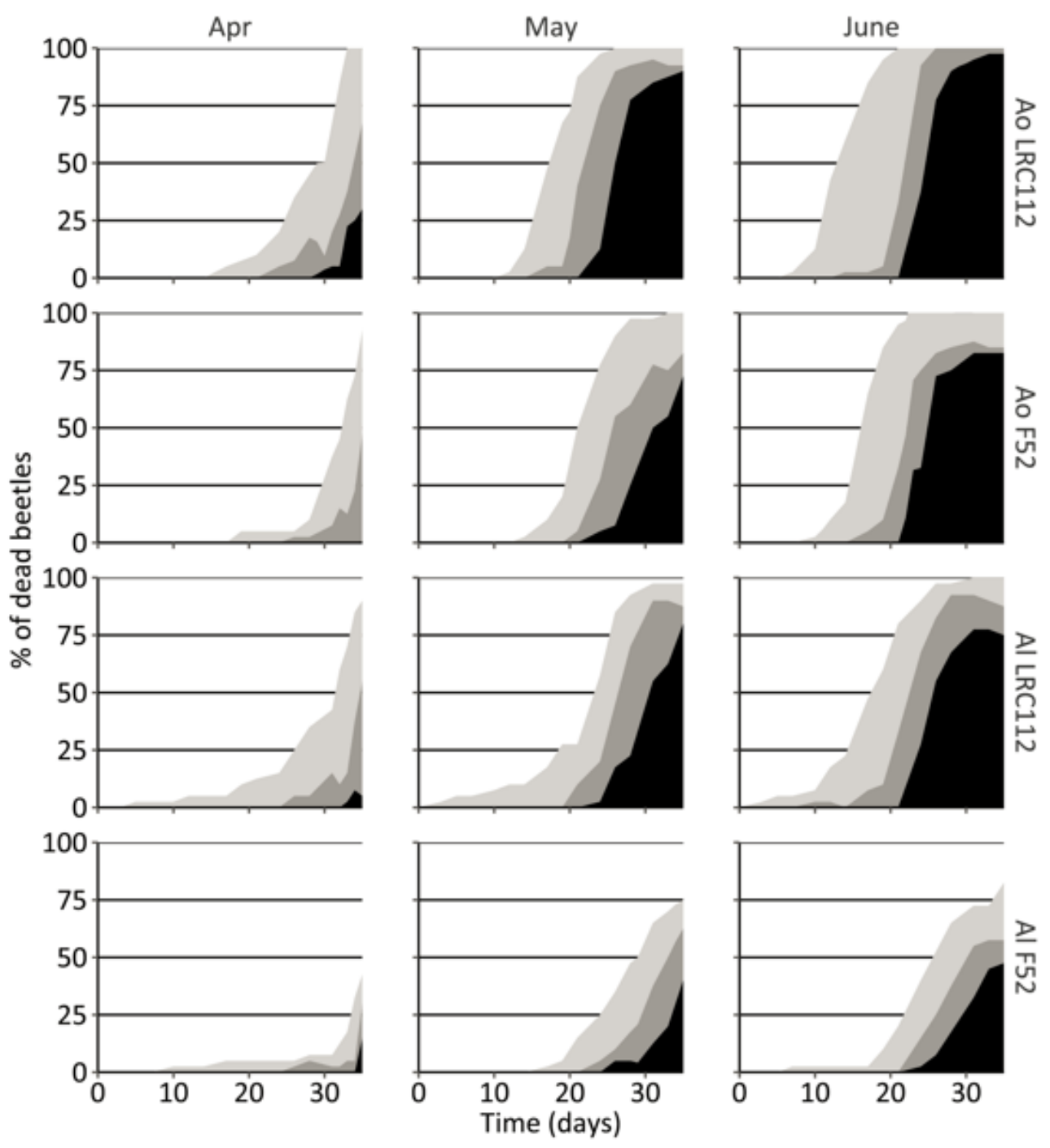

Fig. 4 Mean percent beetle mortality and disease development as a function of time for Agriotes obscurus and A. lineatus exposed to M. brunneum strains LRC112 and F52 and temperature profiles for April, May, and June. Disease development categories are asymptomatic dead beetles ( $\square$ ), mycelial growth $(\square)$ and sporulation ( $\square$ ). The April plates were moved to a $25 \mathrm{C}$ incubator day 31

Figure 4

See image above for figure legend 

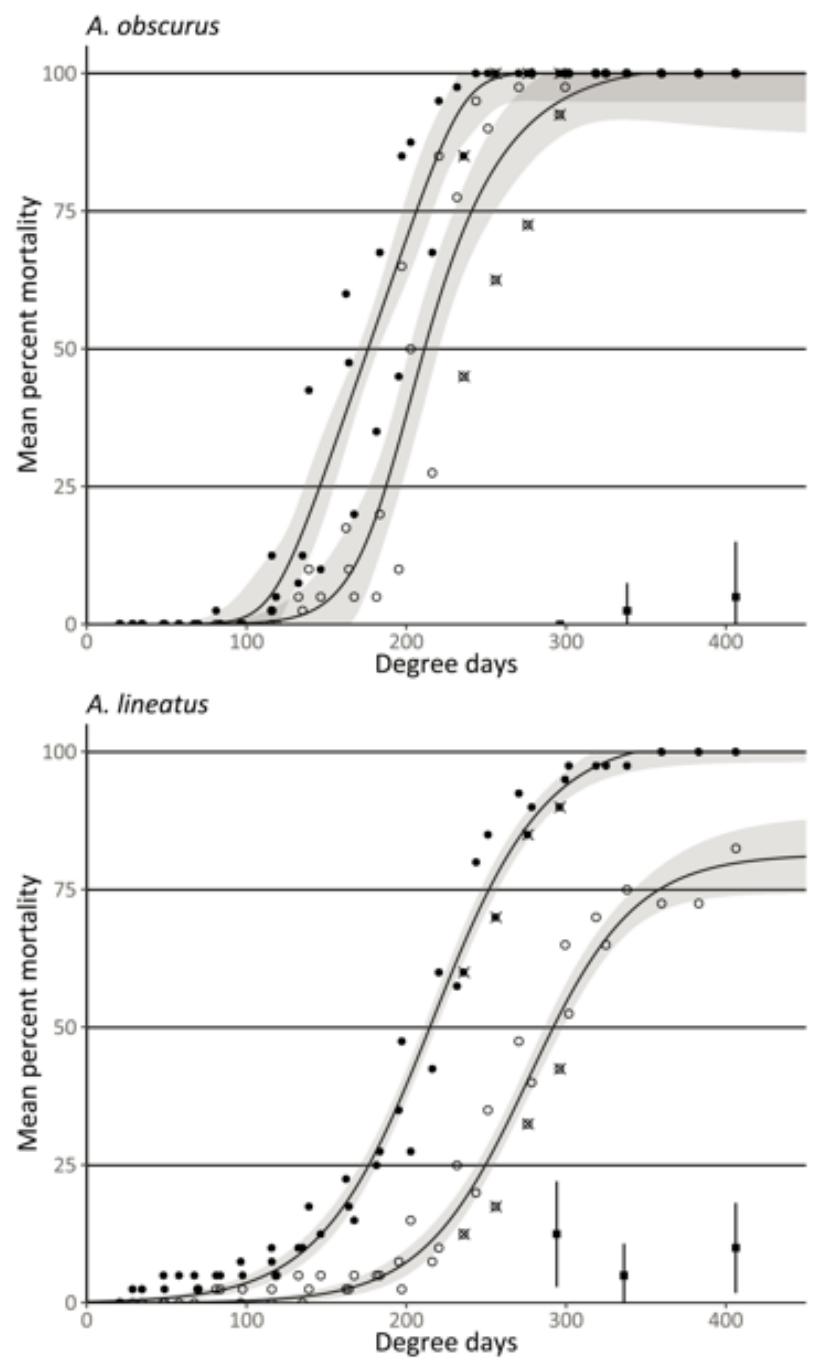

Fig. 5 Mean percent beetle mortality as a function of degree days for Agriotes obscurus and A. lineatus exposed to Metarhizium brunneum strains LRC112 and F52. The shaded area denotes the $95 \%$ confidence interval for the regression line. M. brunneum LRC112 (•) and M. brunneum F52 (0). Dashed lines and associated values are interpolations of the number of lethal degree days to kill $50 \%$ of the beetle population $\left(\mathrm{LDD}_{50}\right)$. Plates in April that were moved to a $25 \mathrm{C}$ incubator are marked with a cross ( (x)

\section{Figure 5}

See image above for figure legend 

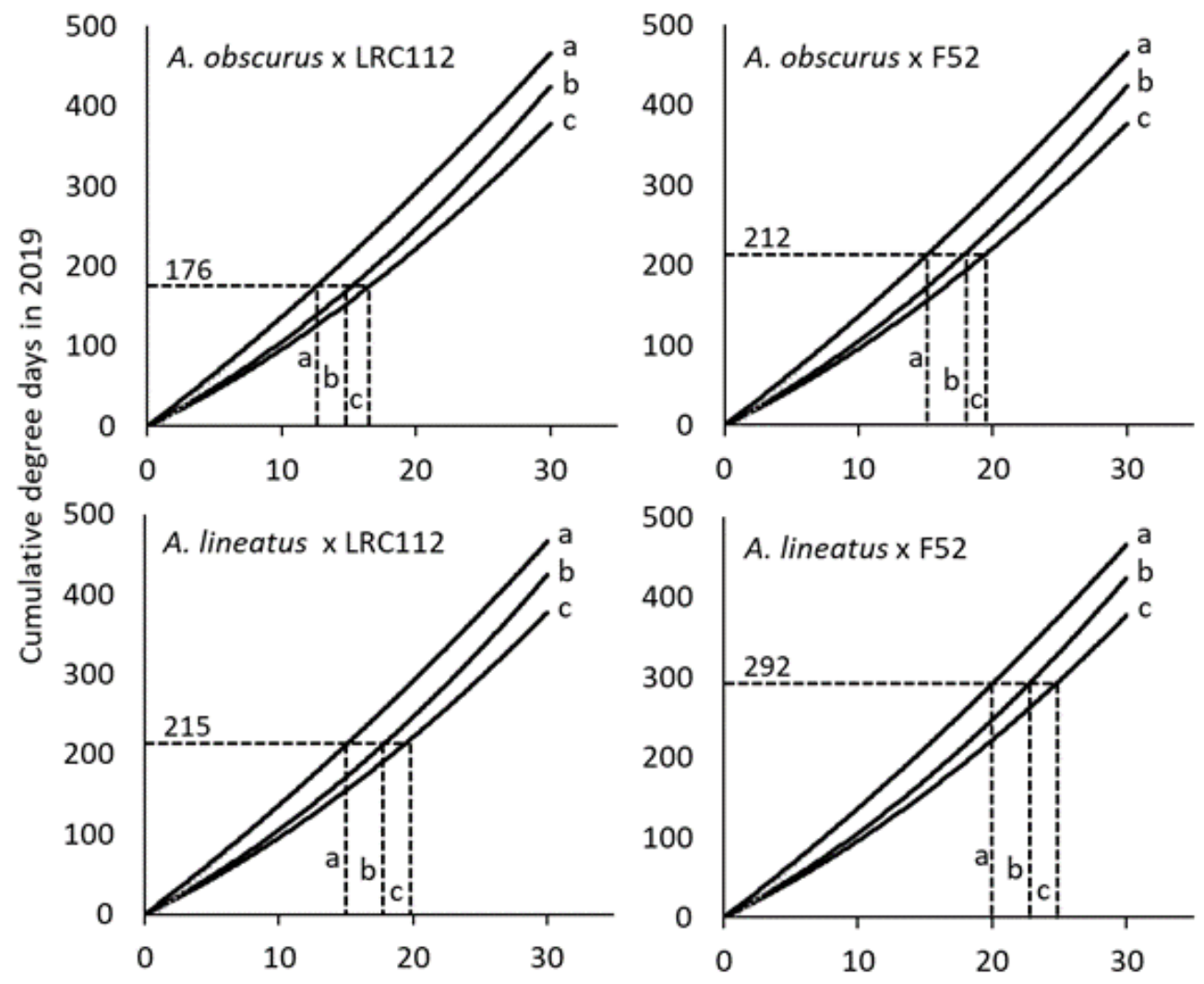

Number of days after hypothetical Metarhizium brunneum exposure

\begin{tabular}{|c|c|c|c|c|c|}
\hline $\begin{array}{l}\text { Beetle species } x \\
\text { M. brunneum strain }\end{array}$ & $\begin{array}{l}\mathrm{LDD}_{5} \\
0\end{array}$ & & $\begin{array}{l}\text { Hypothetical } \\
\text { M. brunneum } \\
\text { exposure date }\end{array}$ & $\mathrm{LT}_{\mathrm{s0}}$ (days) & Date of $L T_{s o}$ \\
\hline \multirow[t]{3}{*}{ A. obscurus $\times$ LRC112 } & 176 & a & April 15 & 17 & May 2 \\
\hline & & $\mathrm{b}$ & April 22 & 16 & May 8 \\
\hline & & c & April 29 & 12 & May 11 \\
\hline \multirow[t]{3}{*}{ A. obscurus x F52 } & 212 & a & April 15 & 20 & May 5 \\
\hline & & $b$ & April 22 & 18 & May 10 \\
\hline & & c & April 29 & 15 & May 14 \\
\hline \multirow[t]{3}{*}{ A. lineautus $\times$ LRC112 } & 215 & a & April 15 & 20 & May 5 \\
\hline & & $\mathrm{b}$ & April 22 & 18 & May 10 \\
\hline & & c & April 29 & 15 & May 14 \\
\hline \multirow[t]{3}{*}{ A. lineatus $x \mathrm{F5} 2$} & 292 & a & April 15 & 25 & May 10 \\
\hline & & $\mathrm{b}$ & April 22 & 22 & May 14 \\
\hline & & c & April 29 & 20 & May 19 \\
\hline
\end{tabular}

\section{Figure 6}

Lethal time (days) to kill $50 \%$ of beetles (LT50) based on LDD50 values (Fig. 4) and hypothetical dates of exposure of Agriotes obscurus and A. lineatus to Metarhizium brunneum strains LRC112 and F52. Lines a, b, and c refer to the three hypothetical application dates: April 15, April 22, and April 29, respectively 